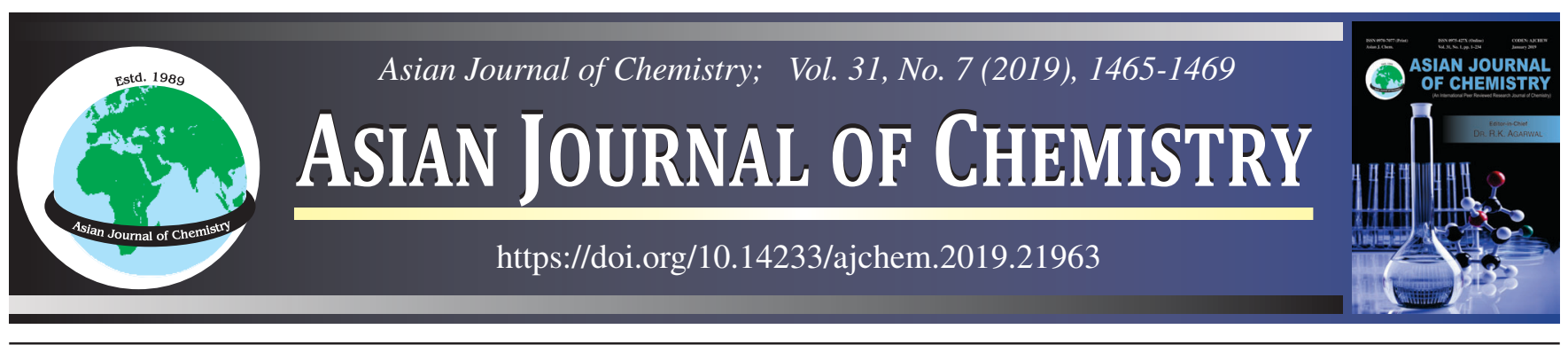

\title{
Analytical Solutions and Neural Network Modelling for Removal of Chromium(VI) from Industrial Wastewater using Carissa carandas
}

\section{P. Sirisha ${ }^{1, *}$, SaYeeda Sultana ${ }^{1}$ and P. Gopikrishna ${ }^{2}$}

${ }^{1}$ Department of Chemistry, St. Peter's Institute of Higher Education and Research (Deemed to be University) Avadi, Chennai-600054, India ${ }^{2}$ College of Electrical and Mechanical Engineering, Addis Ababa Science and Technology University, Addis Ababa, Ethiopia

*Corresponding author: E-mail: rishipragnatha@gmail.com

Received: 27 January 2019;

Accepted: 10 February 2019;

Published online: 21 May 2019;

AJC-19397

The main objective of this paper is to investigate and estimate the capacity of low cost bio-sorbent Carissa carandas in removing
chromium from industrial wastewater using analytical techniques and artificial neural networks (ANN). As an application to real time
wastewater treatment, in this paper, the adsorption capacity of Carissa carandas for the removal of Cr(VI) ions from local industrial
wastewater was investigated using atomic adsorption spectroscopy (AAS), scanning electron microscope (SEM), Fourier transform infrared
spectroscopy (FTIR) and X-ray diffraction (XRD). We proposed an artificial intelligent technique based radial basis function neural
network, which is used to model the obtained experimental results to estimate the percentage removal of Cr(VI) for different unknown
metal ion concentrations. The adsorption of Cr(VI) from local industrial wastewater by Carissa carandas prepared by chemical method.
It was analyzed using Langmuir, Freundlich isotherms and pseudo-first and second order kinetic models. The percentage of adsorption
was investigated using effect of adsorbent dose, initial adsorbate concentration, pH and contact time. The results obtained from the
investigations show that the maximum adsorption of hexavalent chromium by Carissa carandas was found as $96 \%$ at 5 ppm, 120 min,
1 g/L of adsorbent dosage and pH = 5 and $95.81 \%$ through artificial neural networks for same parameters. As Carissa carandas is
abundantly available free of cost at many places so this research outcome will be effectively and economically useful for the wellbeing of
ocean and land environment.

| Keywords: Adsorption isotherms, Carissa carandas, Hexavalent chromium, Neural Network modeling.

ᄂ - - - - - - - - - - - - - - - - - - - - - - - - - - - - -

\section{INTRODUCTION}

Heavy metals, such as chromium, cadmium, copper, mercury and lead are causing main environmental pollution when compared with other heavy metals. Generally the metal pollution issues are quite common at many places in India and in other places across the world, with several recognized evidences of toxic metals in various industries like leather, thermal power plants, mining, smelters, foundries and agriculture. The usage of heavy metals in soils beyond its permissible limits in agricultural production causes severe effects on crop growth, market ability and food safety. The redistribution of heavy metals geologically and biologically causes heavy metal pollution in water, air soil, which affects the metabolic activities of the plants. The study on heavy metal toxicity and it's permissible limits in plants indicates the enhancing of metal pollution in the environment is discussed by Nagajyoti et al. [1]. Some metals like chromium, copper, cobalt, manganese and zinc are necessary for plant metabolism. It is possible only when the heavy metals are existent in bioavailable forms and within the specified permissible limited levels, if level exceeds they become toxic to the plants and people.

In the modern society, to enhance the human living standards, many industries have been using chromium compounds and without appropriate treatment of discharge of those chemicals into the environment opposite the future living standard. Leather tanning industries are ranked as the main contributors of chromium pollution [2]. The wide usage of chromium in various industries causes $\mathrm{Cr}(\mathrm{VI})$ contamination which leads to more frightening to the environment. Therefore, the treatment of heavy metal ions existing in wastewaters through novel methods is becoming a significant in the modern society. Adsorption is a most popular

This is an open access journal, and articles are distributed under the terms of the Creative Commons Attribution-NonCommercial-ShareAlike 4.0 (CC BY-NC-SA 4.0) International License which allows readers to freely read, download, copy, distribute, print, search, or link to the full texts of its articles and to use them for any other lawful non-commercial purpose as long as the original source is duly acknowledged. 
technique for examining the removal of heavy metals as stated by Sushovan et al. [3].

Since many years the adsorption method is well known to the researchers, and it has been extensively utilized to get bulk separation of metal ions. In general, the porous solid medium is the main part of an adsorption process and it is a critical variable. The porous solid of a given adsorption process is a critical variable. The success rate of the adsorption process is relying on the behaviour of solid in both kinetics and equilibrium. A good capacity solid with slow kinetics is not a good choice because adsorbate molecules take more time to reach the interior particle. That means lengthy gas dwelling time in a column, which leads to low output. In contrast, a low capacity solid with swift kinetics is not preferable as a big quantity of solid is essential for a specified output. Thus, a good solid as an adsorbent exhibits good adsorptive capacity and decent kinetics as described by Do [4]. In the literature various adsorption analysis techniques have been proposed and used for the estimation of equilibrium and kinetics. The gas solid phase adsorption onto activated carbon was explained primarily by the Langmuir adsorption isotherm and it has been conventionally been used to measure and compare the performance of various biosorbents. As per the Langmuir sorption isotherm [5], the most of the adsorption happens when a saturated monolayer of solute molecules is present on the adsorbent surface, there is no migration of adsorbate molecules in the surface plane when the energy of adsorption is constant. The Freundlich adsorption isotherm [6] is the initial isotherm which discusses the mathematical relationship for reversible and non-ideal adsorption. The theory of this model is not limited to the formation of a monolayer. For the multilayer adsorption, experiential model can be relevant with non-uniform distribution of adsorption over the heterogeneous surface [7].

Since from last few decades, artificial neural network (ANN) has been evolving and applying in the multi-discipline applications and with millions of applications. The ANN is proved as the best model the empirical data obtained through different testing procedures. The ANN based model developed on experimental points specified that the model can forecast removal of $\mathrm{Cr}(\mathrm{VI})$ for various operating conditions with reasonably high accuracy [3]. An ANN model was established to predict the percentage removal of $\mathrm{Cr}(\mathrm{VI})$ from aqueous solution using a Borasus flabellifer coir powder as adsorbent. The effect of working parameters such as $\mathrm{pH}$, adsorbent dosage and initial $\mathrm{Cr}(\mathrm{VI})$ concentration are considered to enhance the conditions for the maximum removal of $\mathrm{Cr}(\mathrm{VI})$ ions. The ANN model was established using 54 experimental data points for training and 16 data points for testing by a single layer feed forward back propagation network with 18 neurons to get minimum mean squared error (MSE). A tansigmoid and a purelin were used as a transfer function for input and output layers, respectively. The correlation coefficient between the experimental data and the model showed that the ANN model was able to expect the removal of $\mathrm{Cr}(\mathrm{VI})$ from aqueous solution using Borasus flabellifer coir powder efficiently [8].

A multilayer feed forward artificial neural network (ANN) model used to predict the adsorption efficiency and adsorption capacity for the removal of $\mathrm{Cr}(\mathrm{VI})$ from synthetic wastewater.
The wastewater $\mathrm{pH}$, dosage of adsorbent, initial metal concentration and contact time were used to develop the ANN. The training and checking data used to train and test the model were obtained from different batch experiments, respectively. Several intelligent algorithms and activation functions for hidden layer were tested to identify the utmost reliable network. Back-propagation algorithm gave the best acceptable results for adsorption capacity and adsorption efficiency. The best activation function for the adsorption efficiency was found to be trainrp and poslin. The poslin transfer function gave the simulated results within $10 \%$ deviation for adsorption capacity. The optimum number of neurons was found to be 8 to 11 using trial and error method [9].

Adsorption of heavy metals using Carissa carandas have been reported by authors in their research work [10-12] and adsorption of $\mathrm{Cr}(\mathrm{VI})$ and its analytical applications are also reported $[13,14]$. In this paper, we proposed an artificial intelligent technique based radial basis function neural network, which is used to model the obtained experimental results to estimate the percentage removal of $\mathrm{Cr}(\mathrm{VI})$ for different unknown metal ion concentrations using Carissa carandas.

\section{EXPERIMENTAL}

In this paper, leaves of Carissa carandas plant were used as an adsorbent for the removal $\mathrm{Cr}(\mathrm{VI})$ from aquatic solutions. The leaves are washed thoroughly under tap water, after that washed again thoroughly with distilled water and dried finally for 15 days under sunlight. The dried leaves became completely crispy and then grinded, filtered to get fine powder.

The known concentration of $\mathrm{Cr}(\mathrm{VI})$ solution ranging from 5 to $25 \mathrm{ppm}$ was prepared using analytical grade potassium dichromate. Synthetic samples of different concentrations of $\mathrm{Cr}(\mathrm{VI})$ are prepared from this stock solution with appropriate dilutions.

The analysis of batch adsorption process were performed to measure the optimum time required to reach saturation. Batch adsorption kinetics studied at varied $\mathrm{Cr}(\mathrm{VI})$ concentration

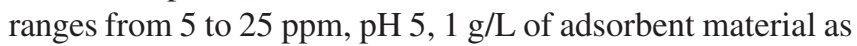
Carissa carandas and varied contact time from 20 to $120 \mathrm{~min}$ with interval $20 \mathrm{~min}$. After each $20 \mathrm{~min}$, samples were collected filtered, centrifuged and $\mathrm{Cr}(\mathrm{VI})$ concentrations were analyzed by UV-visible spectrophotometer at $540 \mathrm{~nm}$ using diphenylcarbazide method. The $\mathrm{Cr}(\mathrm{VI})$ uptake was calculated in terms of percentage using eqn. 1 :

$$
\operatorname{Removal}(\%)=\frac{\mathrm{C}_{\mathrm{o}}-\mathrm{C}_{\mathrm{e}}}{\mathrm{C}_{\mathrm{o}}} \times 100
$$

where, $\mathrm{C}_{\mathrm{e}}$ and $\mathrm{C}_{\mathrm{o}}$ are the final and initial concentration of heavy metal, respectively. The adsorption capacity $\mathrm{q}_{\mathrm{e}}(\mathrm{mg} / \mathrm{g})$ was calculated using eqn. 2 :

$$
\mathrm{q}_{\mathrm{e}}=\left(\mathrm{C}_{\mathrm{o}}-\mathrm{C}_{\mathrm{e}}\right) \frac{\mathrm{V}}{\mathrm{W}}
$$

where, $\mathrm{V}$ is the volume of solution (L) and $\mathrm{W}$ is the mass of adsorbent (g).

Adsorption modelling: The parameters such as adsorbent dosage, adsorbate concentration, equilibrium concentration, contact time, reaction rate, pressure, etc. are involved in the 
adsorption process. The magnitude of adsorbate adsorbed on the surface of adsorbent is estimated using this parameter. The Freundlich and Langmuir isotherm models are only relevant to batch adsorption systems where adequate time is provided to allow equilibrium between the adsorbate in solution and the adsorbate adsorbed on the media to occur.

Freundlich model: The experimental data on $\mathrm{Cr}(\mathrm{VI})$ adsorption were fitted to the Freundlich adsorption isotherm model which can be expressed using eqn. 3 :

$$
\mathrm{Q}_{\mathrm{e}}=\mathrm{K}_{\mathrm{f}} \mathrm{C}^{1 / \mathrm{n}}
$$

Equation 3 is rearranged as:

$$
\log \mathrm{q}_{\mathrm{e}}=\log \mathrm{K}_{\mathrm{f}}+\frac{1}{\mathrm{n}} \log \mathrm{C}_{\mathrm{e}}
$$

where $\mathrm{q}_{\mathrm{e}}$ the adsorption capacity $(\mathrm{mg} / \mathrm{g})$ at equilibrium, $\mathrm{C}_{\mathrm{e}}$ is $\mathrm{Cr}(\mathrm{VI})$ ion concentration in solution at equilibrium $(\mathrm{mg} / \mathrm{L})$. The Freundlich adsorption isotherm, physical constants are n, $\mathrm{K}_{\mathrm{f}}$, are the indicators of adsorption intensity and adsorption capacity, respectively.

Langmuir model: The experimental data on $\mathrm{Cr}(\mathrm{VI})$ adsorption were fitted to the Langmuir adsorption isotherm model which can be expressed as follows:

$$
\frac{\mathrm{C}_{\mathrm{e}}}{\mathrm{q}_{\mathrm{e}}}=\frac{1}{\mathrm{Q}_{\mathrm{o}} \mathrm{b}}+\frac{\mathrm{C}_{\mathrm{e}}}{\mathrm{Q}_{\mathrm{o}}}
$$

where, $C_{e}(\mathrm{mg} / \mathrm{L})$ is denoted as concentration equilibrium of $\mathrm{Cr}(\mathrm{VI})$ ions in the solution present, at equilibrium $\mathrm{q}_{\mathrm{e}}(\mathrm{mg} / \mathrm{g})$ is the adsorption capacity, the maximum adsorption capacity is $\mathrm{Q}_{0}(\mathrm{mg} / \mathrm{g})$ and $\mathrm{b}$ is the Langmuir adsorption constant $\left(\mathrm{L} \mathrm{mg}^{-1}\right)$.

\section{Adsorption kinetics}

Pseudo-first order model: The kinetics of sorption process is understood with the different rate equation to fit the empirical data for any kind of sorption [15].

The chromium (VI) adsorption kinetics on Carissa carandas powder was studied with varies parameters such as contact time, $\mathrm{pH}$, dosage of adsorbent and $\mathrm{Cr}(\mathrm{VI})$ ion concentration. The kinetics of $\mathrm{Cr}(\mathrm{VI})$ adsorption in Carissa carandas powder experimental data were correlated to pseudo-first and second order model. The most widely used equation for pseudo firstorder model is shown in eqn 6:

$$
\log \left(\mathrm{q}_{\mathrm{e}}-\mathrm{q}_{\mathrm{t}}\right)=\log \mathrm{q}_{\mathrm{e}}-\frac{\mathrm{K}_{\mathrm{l}} \mathrm{t}}{2.303}
$$

where, $\mathrm{q}_{\mathrm{t}}$ is the mass of metal adsorbed at time $\mathrm{t}(\mathrm{mg} / \mathrm{g}), \mathrm{q}_{\mathrm{e}}$ is the mass of metal ion adsorbed at equilibrium $\left(\mathrm{mg} / \mathrm{g}\right.$ ) and $\mathrm{K}_{1}$ is the first order reaction rate constant (per minute).

Pseudo-second order model: The utmost commonly used rate equation for the sorption of a solute from a liquid phase is the pseudo-second order equation. Practically, pseudo-second order rate constants are determined by plotting t/qt $v s$. t. Even though several factors influences the adsorption capacity such as initial concentration of adsorbents, the temperature reaction, adsorbate $\mathrm{pH}$, adsorbent dosage, particle size and the nature of adsorbents. A kinetic model is concerned with the effect of apparent parameters on the overall rate. The method of least squares is used for finding parameters of the kinetic models and linear regressions are mostly used to determine the best fitting kinetic models. Regression analysis is used to determine the different parameters through the five forms of pseudo- second order model. Pseudo-second order model [16] is established on equilibrium adsorption capacity as follows:

$$
\frac{\mathrm{t}}{\mathrm{q}_{\mathrm{t}}}=\frac{1}{\mathrm{~K}_{2} \mathrm{q}_{\mathrm{e}}^{2}}+\frac{\mathrm{t}}{\mathrm{q}_{\mathrm{e}}}
$$

where, $\mathrm{K}_{2}$ is the second order reaction rate constant $((\mathrm{g} / \mathrm{mg})$ $\min ^{-1}$ ).

Artificial neural networks model: Artificial neural networks (ANN) is an emerging artificial intelligence technique. The radial basis function neural network (RBFNN) is one of the techniques of ANN. The RBFNN is a hugely parallel information processing system and can perform non-linear calculations in a short duration when it has trained with the adequate data. After RBFNN trained until the mean squared error becomes zero, then RNFNN said be trained with the existing empirical data for the removal $\mathrm{Cr}(\mathrm{VI})$ using Carissa carandas, now the trained RBFNN can able to estimate the percentage removal of $\mathrm{Cr}(\mathrm{VI})$ for unknown adsorbent dosages [17]. The radial basis function (RBF) is represented with eqn. 8 and used as an activation function for the hidden neurons in RBFNN.

$$
\varphi=\exp \left(-\frac{\sum_{\mathrm{i}=1}^{\mathrm{n}}\left(\mathrm{x}_{\mathrm{i}}-\mathrm{w}_{\mathrm{ij}}\right)^{2}}{2 \sigma^{2}}\right)
$$

\section{RESULTS AND DISCUSSION}

The results of Freundlich and Langmuir isotherms are shown in Table-1. However, the data in Table-2 show that the Langmuir isotherm suit well than Freundlich isotherm.

TABLE-1

FREUNDLICH AND LANGMUIR ISOTHERMS DATA

\begin{tabular}{cc|cc}
\hline \multicolumn{2}{c|}{ Freundlich isotherms } & \multicolumn{2}{c}{ Langmuir isotherms } \\
\hline $\log \mathrm{q}_{\mathrm{e}}$ & $\log \mathrm{c}_{\mathrm{e}}$ & $\mathrm{C}_{\mathrm{e}} / \mathrm{q}_{\mathrm{e}}$ & $\mathrm{C}_{\mathrm{e}}$ \\
\hline 0.681241 & -0.69897 & 0.041667 & 0.2 \\
0.959041 & -0.04576 & 0.098901 & 0.9 \\
1.113943 & 0.30103 & 0.153846 & 2 \\
1.204120 & 0.60206 & 0.25 & 4 \\
1.278754 & 0.880814 & 0.4 & 7.6 \\
\hline
\end{tabular}

First order (adsorption) kinetic model: The plot of log $\left(\mathrm{q}_{\mathrm{e}}-\mathrm{q}_{\mathrm{t}}\right)$ versus $\mathrm{t}$ indicates the application of the first-order kinetic model for Carissa carandas powder as shown in Fig. 1 based on the data presented in Table-3.

TABLE-2

LANGMUIR AND FREUNDLICH ISOTHERM MODELS AND CORRELATION COEFFICIENTS FOR THE ADSORPTION OF CHROMIUM(VI) ON Carissa carandas

\begin{tabular}{ccccc|ccc}
\hline \multirow{2}{*}{$\begin{array}{c}\text { Adsorbent } \\
(\mathrm{g} / \mathrm{L})\end{array}$} & $\mathrm{R}_{\mathrm{L}}$ & \multicolumn{3}{c|}{ Langmuir isotherm } & \multicolumn{3}{c}{ Freundlich isotherm } \\
\cline { 2 - 7 } & & $\mathrm{Q}_{\mathrm{o}}(\mathrm{mg} / \mathrm{g})$ & $\mathrm{b}(\mathrm{L} / \mathrm{mg})$ & $\mathrm{R}^{2}$ & $\mathrm{~K}_{\mathrm{f}}(\mathrm{mg} / \mathrm{g})$ & $\mathrm{n}$ & $\mathrm{R}^{2}$ \\
\hline 1 & 0.170 & 21.22 & 0.9735 & 0.9918 & 9.27 & 2.60 & 0.9906 \\
\hline
\end{tabular}




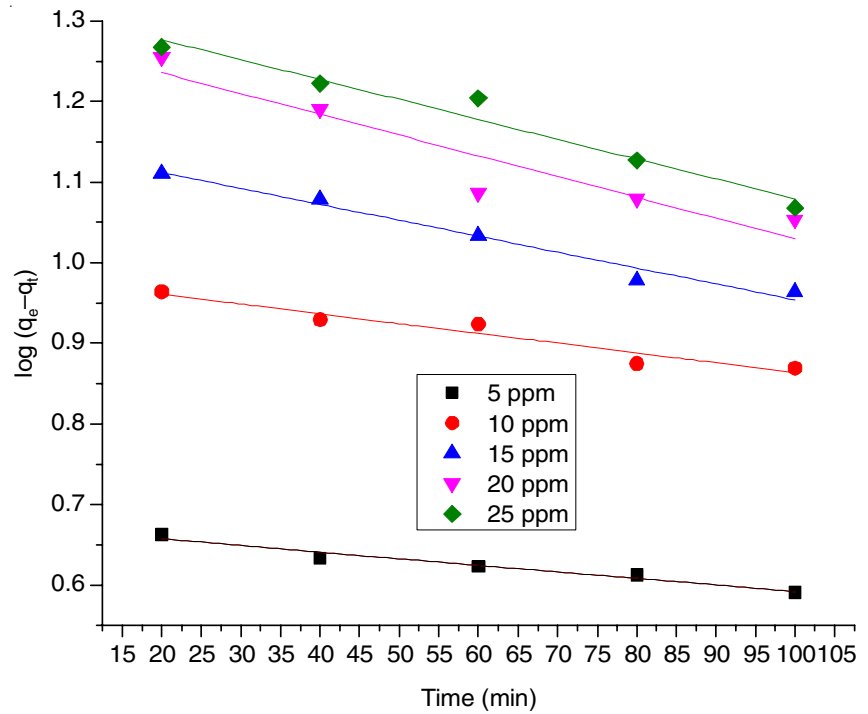

Fig. 1. Variation of $\mathrm{C}_{\mathrm{e}} / \mathrm{q}_{\mathrm{e}} v s$. $\mathrm{C}_{\mathrm{e}}$

\begin{tabular}{cccccc}
\multicolumn{7}{c}{ TABLE-3 } \\
\multicolumn{7}{c}{$\begin{array}{c}\text { PSEUDO-FIRST-ORDER KINETIC MODEL OF } \\
\text { Carissa carandas FOR REMOVAL Cr(VI) }\end{array}$} \\
\hline Time & \multicolumn{5}{c}{$\log \left(\mathrm{q}_{\mathrm{e}}-\mathrm{q}_{\mathrm{t}}\right)$} \\
\cline { 2 - 6 }$(\mathrm{min})$ & $5 \mathrm{ppm}$ & $10 \mathrm{ppm}$ & $15 \mathrm{ppm}$ & $20 \mathrm{ppm}$ & $25 \mathrm{ppm}$ \\
\hline 20 & 0.6627578 & 0.963788 & 1.11059 & 1.255273 & 1.267172 \\
40 & 0.6334684 & 0.929419 & 1.079181 & 1.190332 & 1.222716 \\
60 & 0.6232492 & 0.924279 & 1.033424 & 1.08636 & 1.20412 \\
80 & 0.6127838 & 0.875061 & 0.977724 & 1.079181 & 1.127105 \\
100 & 0.5910646 & 0.869232 & 0.963788 & 1.053078 & 1.068186 \\
\hline
\end{tabular}

Pseudo-second order model: A graph (Fig. 2) was plotted $\mathrm{t} / \mathrm{q}_{\mathrm{t}}(\mathrm{min}(\mathrm{g} / \mathrm{mg}))$ versus $\mathrm{t}(\mathrm{min})$ indicates the application of second-order kinetic model for Carissa carandas powder. The parameters obtained are given in Table- 4 by comparing the models based on linear regression values. The kinetics of $\mathrm{Cr}^{6+}$ ion adsorption on Carissa carandas powder can be described by pseudo second-order kinetics.

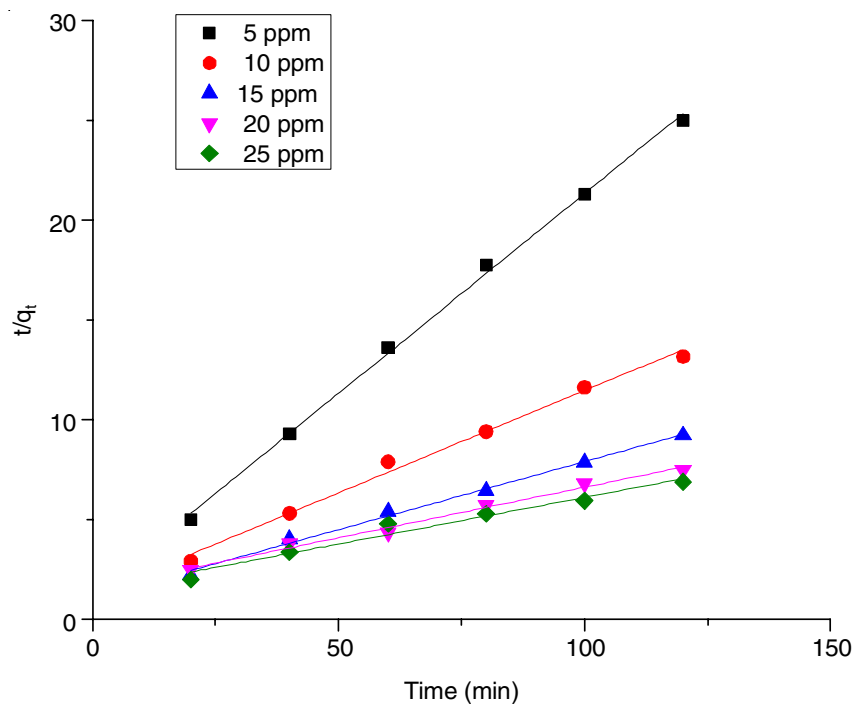

Fig. 2. Variation of $\mathrm{C}_{\mathrm{e}} / \mathrm{q}_{\mathrm{e}} v s . \mathrm{C}_{\mathrm{e}}$

Artificial neural network: The data shown in Table-5 is obtained through the effective training of RBFNN with an

\begin{tabular}{|c|c|c|c|c|c|}
\hline \multicolumn{6}{|c|}{$\begin{array}{c}\text { TABLE-4 } \\
\text { PSEUDO SECOND ORDER KINETIC MODEL OF Carissa carandas FOR REMOVAL OF Cr(VI) }\end{array}$} \\
\hline \multirow{2}{*}{ Time (min) } & \multicolumn{5}{|c|}{$\mathrm{t} / \mathrm{q}_{\mathrm{t}}$} \\
\hline & $5 \mathrm{ppm}$ & $10 \mathrm{ppm}$ & $15 \mathrm{ppm}$ & $20 \mathrm{ppm}$ & $25 \mathrm{ppm}$ \\
\hline 20 & 5.000000 & 2.941176 & 2.222222 & 2.500000 & 2.000000 \\
\hline 40 & 9.302326 & 5.333333 & 4.040404 & 3.809524 & 3.389831 \\
\hline 60 & 13.636360 & 7.894737 & 5.405405 & 4.347826 & 4.800000 \\
\hline 80 & 17.777780 & 9.411765 & 6.451613 & 5.714286 & 5.298013 \\
\hline 100 & 21.276600 & 11.62791 & 7.874016 & 6.802721 & 5.952381 \\
\hline 120 & 25.000000 & 13.18681 & 9.230769 & 7.500000 & 6.896552 \\
\hline \multicolumn{6}{|l|}{ Pseudo first order } \\
\hline $\mathrm{K}_{1}\left(\min ^{-1}\right)$ & 0.0019 & 0.0028 & 0.0045 & 0.0059 & 0.0056 \\
\hline $\mathrm{q}_{\mathrm{e}}(\mathrm{mg} / \mathrm{g})$ & 4.71 & 9.66 & 14.17 & 19.38 & 21.18 \\
\hline $\mathrm{R}^{2}$ & 0.9612 & 0.9366 & 0.9755 & 0.895 & 0.9636 \\
\hline \multicolumn{6}{|l|}{ Pseudo second order } \\
\hline $\mathrm{K}_{2}(\mathrm{~g} / \mathrm{mg}) \mathrm{min}^{-1}$ & 0.030 & 0.0084 & 0.0041 & 0.0016 & 0.0014 \\
\hline $\mathrm{q}_{\mathrm{e}}(\mathrm{mg} / \mathrm{g})$ & 4.99 & 9.77 & 14.70 & 19.80 & 21.42 \\
\hline $\mathrm{R}^{2}$ & 0.9982 & 0.993 & 0.9949 & 0.9901 & 0.9671 \\
\hline
\end{tabular}

TABLE-5

ARTIFICIAL NEURAL NETWORKS BASED \% REMOVAL OF Cr(VI) (5 ppm) FOR DIFFERENT ADSORBENT CONTACT TIMES

\begin{tabular}{|c|c|c|c|c|c|c|c|}
\hline \multirow{2}{*}{$\begin{array}{l}\text { Actual contact } \\
\text { time (min) }\end{array}$} & \multicolumn{3}{|c|}{$\%$ Removal of $\mathrm{Cr}(\mathrm{VI})$ for $5 \mathrm{ppm} \mathrm{Cr}$ concentration } & \multirow{2}{*}{$\begin{array}{l}\text { Estimated } \\
\text { contact time } \\
(\mathrm{min})\end{array}$} & \multirow{2}{*}{$\begin{array}{l}\text { ANN based \% } \\
\text { removal of } \\
\text { Cr(VI) }\end{array}$} & \multirow{2}{*}{$\begin{array}{c}\text { Estimated } \\
\text { contact time } \\
(\mathrm{min})\end{array}$} & \multirow{2}{*}{$\begin{array}{l}\text { ANN based \% } \\
\text { removal of } \\
\mathrm{Cr}(\mathrm{VI})\end{array}$} \\
\hline & Actual & Predicted & Avg. error & & & & \\
\hline 0 & 0 & 0 & 0 & 5 & 79.9791 & 50 & 83.3714 \\
\hline 20 & 80 & 80 & 0 & 10 & 79.9791 & 70 & 83.3317 \\
\hline 40 & 86 & 86 & 0 & 15 & 79.9800 & 90 & 85.7814 \\
\hline 60 & 88 & 88 & 0 & 25 & 80.2276 & 110 & 87.2463 \\
\hline 80 & 90 & 90 & 0 & 30 & 81.4356 & 119 & 95.8114 \\
\hline 100 & 94 & 94 & 0 & 35 & 84.1882 & 125 & 91.1956 \\
\hline 120 & 96 & 96 & 0 & 45 & 84.5173 & 180 & 79.9791 \\
\hline
\end{tabular}


average error of zero at RBF spread equal to 7 with respect to the experimental readings of first column of Table-5. After this precise training, the \% removal of $\mathrm{Cr}(\mathrm{VI})$ at $5 \mathrm{ppm} \mathrm{Cr}(\mathrm{VI})$ concentration was estimated for the different contact time of Carissa carandas dosage. The results through ANN indicates its effectiveness with respect to Langmuir and Freundlich isotherm models in estimating the \% removal $\mathrm{Cr}(\mathrm{VI})$ using Carissa carandas. The results from ANN indicates that the increasing of contact time increases the \% removal of $\mathrm{Cr}(\mathrm{VI})$ up to $95.81 \%$ at 119 min of contact time, after that its decreasing.

\section{Conclusion}

In this paper, the use of Carissa carandas leaves powder as an adsorbent for the removal of $\mathrm{Cr}(\mathrm{VI})$ from local industrial wastewater using different analytical techniques and radial basis function neural network were discussed. The results obtained through various analytical models using Langmuir and Freundlich isotherms and studied the kinetic behaviour of Carissa carandas in removal of $\mathrm{Cr}(\mathrm{VI})$ using pseudo-first and second-order. Found that the maximum percentage removal of $\mathrm{Cr}(\mathrm{VI})$ as $96 \%$. In order to utilize the advantages artificial neural network in estimating the percentage removal of any toxic metal from the wastewater, different adsorbent contact times were used as an input data and \% removal of $\mathrm{Cr}(\mathrm{VI})$ as an output data and trained until to get average error as zero with this trained RBF neural network.

\section{CONFLICT OF INTEREST}

The authors declare that there is no conflict of interests regarding the publication of this article.

\section{REFERENCES}

1. P.C. Nagajyoti, K.D. Lee and T.V.M. Sreekanth, Environ. Chem. Lett., 8, 199 (2010); https://doi.org/10.1007/s10311-010-0297-8.

2. A.A. Belay, J. Environ. Prot., 1, 53 (2010); https://doi.org/10.4236/jep.2010.11007.

3. S. Sushovan, S. Nandi and S. Dutta, Appl. Water Sci., 8, 148 (2018); https://doi.org/10.1007/s13201-018-0790-y.

4. M. Junaid, M.Z. Hashmi, Y.-M. Tang, R.N. Malik and D.-S. Pei, Scient. Rep., 7, 8848 (2017); https://doi.org/10.1038/s41598-017-09075-7.

5. S. Roy, L. Nagarchi, I. Das, J.M. Achuthananthan and S. Krishnamurthy, J. Toxicol., 2015, 504360 (2015). https://doi.org/10.1155/2015/504360.

6. S. Sharma and P. Malaviya, Curr. World Environ., 9, 721 (2014); https://doi.org/10.12944/CWE.9.3.21.

7. J. Febrianto, A.N. Kosasih, J. Sunarso, Y.-H. Ju, N. Indraswati and S. Ismadji, J. Hazard. Mater, 162, 616 (2009); https://doi.org/10.1016/j.jhazmat.2008.06.042.

8. D. Krishna and R.P. Sree, Int. J. Appl. Sci. Eng., 12, 177 (2014).

9. K. Anupam, S. Dutta, C. Bhattacharjee and S. Datta, Desalination Water Treat., 57, 3632 (2016); https://doi.org/10.1080/19443994.2014.987172.

10. S.K. Sharma, S. Mahiya and G. Lofrano, Appl. Water Sci., 7, 1855 (2017); https://doi.org/10.1007/s13201-015-0359-y.

11. S. Mahiya, S.K. Sharma and G. Lofrano, Cogent Environ. Sci., 2, 1218993 (2016); https://doi.org/10.1080/23311843.2016.1218993.

12. S. Mahiya, G. Lofrano and S.K. Sharma, Chem. Sci. Trans., 3, 1228 (2014); https://doi.org/10.7598/cst2014.884.

13. V.K. Veni and J.V. Rao, Int. J. Res. Eng. Appl. Manage., 18 (2018).

14. P. Sirisha and S. Sultana, Int. J. Res. Anal. Rev., 5, 834 (2018).

15. Y.S. Ho and G. McKay, Chem. Eng. J., 70, 115 (1998); https://doi.org/10.1016/S0923-0467(98)00076-1.

16. Y.S. Ho and A.E. Ofomaja, J. Hazard. Mater., 129, 137 (2006); https://doi.org/10.1016/j.jhazmat.2005.08.020.

17. P.G. Krishna, T.G. Manohar and F. Al-Namiy, Int. J. Electr. Electron. Eng. Res., 3, 261 (2013). 